\title{
Brushless DC Motor Modeling Using Bond Graph Method and Control using LabVIEW
}

\author{
Speed control based calssical PID control
}

\author{
Ammar Alsabbagh \\ Dep. of Mechatronics \\ University of Debrecen \\ Hungary, Debrecen \\ Ammar-alsabbagh-eng@hotmail.com
}

\author{
Dr. Péter T. SZEMES \\ Dep. of Mechatronics \\ University of Debrecen \\ Hungary, Debrecen \\ szemespeter@eng.unideb.hu
}

\author{
Abdulkader Baki \\ Dep. of Mechatronics \\ University of Debrecen \\ Hungary, Debrecen \\ Abd.baki9@gmail.com
}

\begin{abstract}
This paper aims to simulate and control a threephase Brushless DC Motor. Bond Graph method has been used to obtain fast and simple dynamic model. The system has been controlled by classical PID controller. All the paper results were fulfilled using LabVIEW program.
\end{abstract}

Keywords-BLDC motor; LabVIEW; Bond Graph; Simulation and control; PID controller; Dynamic Model.

\section{INTRODUCTION}

The brushless Motor is classified either as AC or DC Motor. However, the AC one is used when its back EMF wave is sinusoidal and DC when its back EMF waveform is Trapezoidal [1].

The Sinusoidal Back-EMF motor needs a high resolution positon sensor because the rotor position must be known at every time instant for optimal operation. It also requires more complex software and hardware. The trapezoidal Back-EMF motor is a more attractive alternative for most applications due its simplicity, lower price [5].

As compared to a conventional DC brush motor, Brushless Dc (BLDC) are Dc brush motors turned inside out, so that the field is on the rotor and the armature is on the stator. In BLDC motor, field excitation is provided by a permanent magnet and commutation is achieved electronically instead of using mechanical commutators and brushes. In BLDC motor, the mechanical 'rotating switch' or commutator/brush gear assembly is replaced by an external electronic switch synchronized to the rotor's position [4].

The BLDC motor was chosen for many reasons. First of all, its high efficiency in operations which comes from no voltage throughout brushes, in addition a free good thermal disposal than conventional DC motor. Moreover, BLDC motor requires less maintenance and attain high reliability. Finally, BLDC motor has high dynamic performance and large speeds and torques comparing with its size and weight [2] \& [3].

Nowadays, BLDC motors are commonly used in different fields; for instance, flying robots and copters, underwater robots, biomedical application, automation application and aircrafts.

\section{BLDC PRINCIPAL OF OPERATION}

As demonstrated in fig 1 the BLDC three phases consists of a rotor, a stator and Three coils. The rotor is a permanent magnet and the stator has a coil arrangement A, B, C. The BLDC works depending on the force interaction between permanent magnet and electro magnet. One of the coils is energized which means the coil will be active and create an electromagnetic field that is led to rotate the opposite core of the rotor for the active coils, in sequence to B then to C. After that, the coil A will be energized with opposite polarity and this operation will repeat and the rotor continues to rotate.

The motor in this case has one drop back, since one coil is energized and the other two coils are not, these two dead coils in this case will produce an energy upon the motor. For conquering that problem. they energize the coils A and B in the same time, that gives the motor a high torque. then $\mathrm{B}$ and $\mathrm{C}$, then $\mathrm{C}$ and $\mathrm{A}$. The gathered force in the BLDC motor confirms that BLDC has a stable natural torque where the two coils are energized in the same time but separately.

The most common method of sensing the rotor position in a BLDC motor is using hall-effect position sensors. The Signal from the position sensors produce a three-digit number that changes every $60^{\circ}$ (electrical degrees) as shown in fig. 2 below, (H1, H2, H3). The figure also shows ideal current and backEMF waveform which they are clarified in the fig. 2 as $\left(e_{a}, e_{b}\right.$ and $e_{a}$ respectively). For a BLDC motor with a trapezoidal back-EMF, it is sufficient to get positon information that is updated at every 60-degree electrical interval, called six steps commutation. The position information is then used to decide the triggering of inverter switches. Generally, three hall-effect sensors are used for a three phase motor. Current commutation is done by a six-step inverter as shown in a simplified from in fig. 3. Table1 shows the switching sequence, the current direction and the position sensor signals 

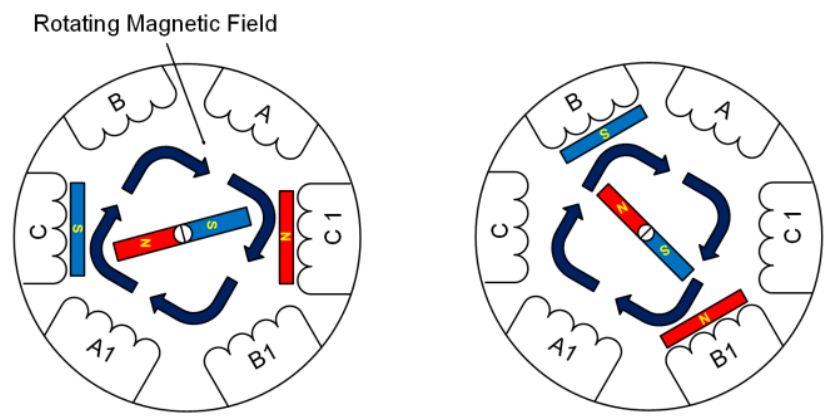

Fig. 1: simplified representation of BLDC motor.

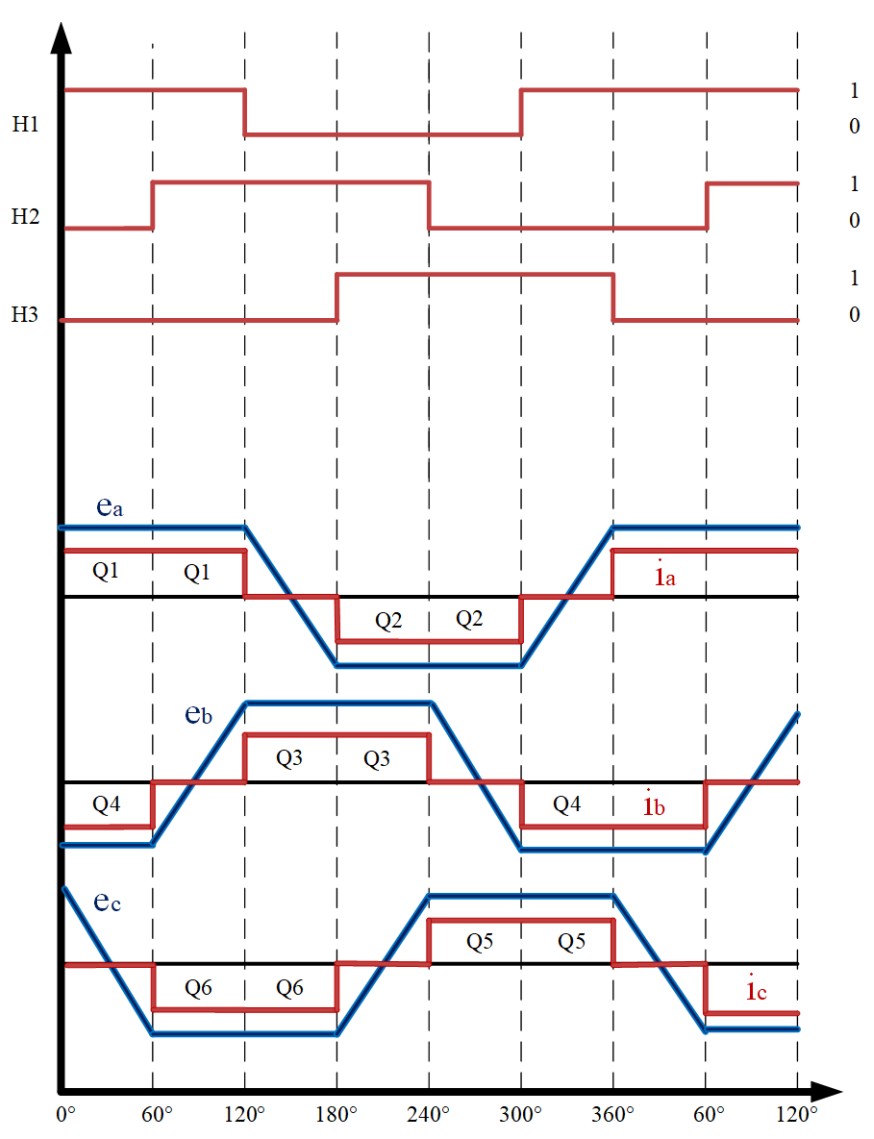

Fig. 2: Back-emf as function of postion (explination).

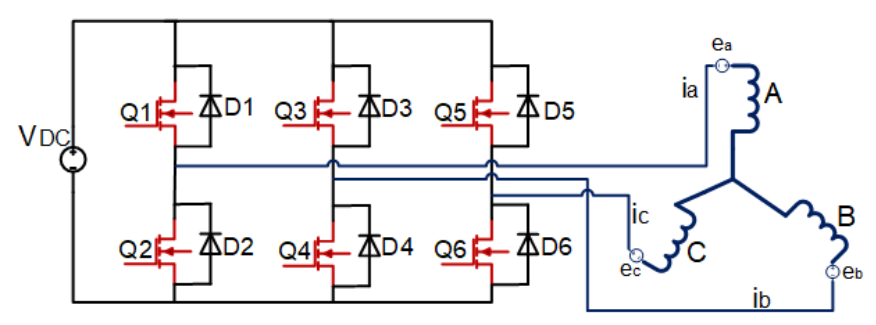

Fig. 3: schematic of BLDC driver (3-phase inverter).
As can be seen in the fig. 3 there are two phases energized by current at the same time leaving the third phase floats. As the following arrangement (AB- AC- BC- BA- CA- $\mathrm{CB}$ ). The hall sensors determine the rotor position.

TABLE 1. SWITCHING SEQUENCE.

\begin{tabular}{|c|c|c|c|c|c|c|c|c|}
\hline \multirow{2}{*}{$\begin{array}{c}\text { Switch } \\
\text { periods }\end{array}$} & \multicolumn{2}{|c|}{ Hall-effect sensors } & \multicolumn{2}{c|}{$\begin{array}{c}\text { On } \\
\text { MOSFET }\end{array}$} & \multicolumn{3}{|c|}{ Phase Current } \\
\cline { 8 - 10 } & H1 & H2 & H4 & \multicolumn{2}{|c|}{ A } & B & C \\
\hline $0-60$ & 1 & 0 & 0 & Q1 & Q4 & + & - & OFF \\
\hline $60-120$ & 1 & 1 & 0 & Q1 & Q6 & + & OFF & - \\
\hline $120-180$ & 0 & 1 & 0 & Q3 & Q6 & OFF & + & - \\
\hline $180-240$ & 0 & 1 & 1 & Q3 & Q2 & - & + & OFF \\
\hline $240-300$ & 0 & 0 & 1 & Q5 & Q2 & - & OFF & + \\
\hline $300-360$ & 1 & 0 & 1 & Q5 & Q4 & OFF & - & + \\
\hline
\end{tabular}

\section{BOND GRAPH MODELING}

Bond graphs is a domain-independent graphical representation of the dynamic acting of physical systems. which means that different domains systems such as (electrical, mechanical, pneumatic/hydraulic, and electromagnetic) are represented using the same way. The key idea behind bond graphs is based on the law of Conservation of Energy "The energy can neither be created nor destroyed; rather, it can only be transformed from one form to another"

Bond graph is a clear graphical tool that describe the common energy structure of systems. It gives better understanding of systems behavior. Furthermore, the notations of causality provide a general view of system behavior, like observability of the system, fault diagnosis and system's controllability [6]. In 1959, Prof. H. M. Paynter gave the radical idea of portraying systems in terms of power bonds, connecting elements of the physical systems to what is called junction constructions which were manifestations of the constraints. This power exchange portray of a system is called Bond Graph, which can be both power and information oriented. Coming after, Bond Graph theory has been further developed by many researchers like Karnopp, Thoma, Rosenberg, and Breedveld, who have worked on extending this modeling technique to mechatronic, power pneumatic, general thermodynamic systems and to electronics and even nonenergetic systems like economics and queuing theory. By this graph, physical systems can be represented by symbols and arrows, representing the power flow paths. The three main parameter elements in Bond Graph are resistance, inertance and compliance are interconnected in an energy conserving way by bonds and junctions resulting in a network structure. From the pictorial representation of the bond graph, the derivation of system equations is so systematic that it can be algorithmized. 


\section{BOND GRAPH MODEL OF BLDC MOTOR}

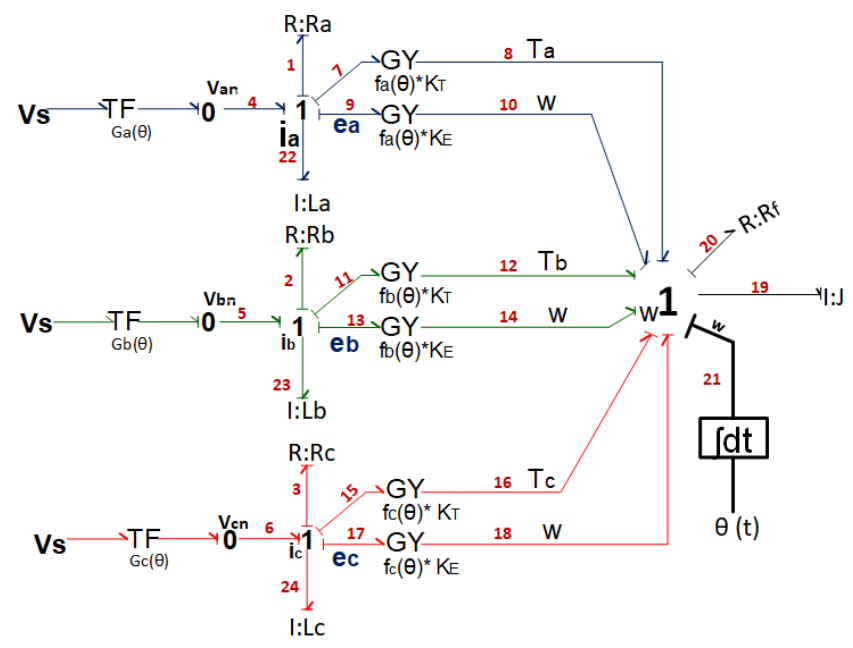

Fig. 4: Bond Graph model of BLDC motor

The differential equations from the Bond graph can be got after numbering, power directing, determining the causality direction.

The following equations are going to express about the elements which mentioned above.

$$
\begin{aligned}
& F_{22}=P h_{1} / L a \\
& F_{23}=P h_{2} / L a \\
& F_{24}=P h_{3} / L a \\
& F_{19}=P h_{4} / J \\
& e_{1}=R_{a} \cdot f_{1}=R_{a} \cdot f_{4}=R_{a} \cdot f_{22} \\
& e_{2}=R_{b} \cdot f_{2}=R_{b} \cdot f_{5}=R_{b} \cdot f_{23} \\
& e_{3}=R_{c} \cdot f_{3}=R_{c} \cdot f_{6}=R_{c} \cdot f_{24} \\
& e_{20}=R_{f} \cdot f_{20}=R_{f} \cdot f_{19}
\end{aligned}
$$

The next equations are going to express about what are the causaliting elements receive from the systems.

$$
\begin{aligned}
& d p h_{1} / d t=e_{22}=e_{4}-e_{1}-e_{9} \\
& d p h_{2} / d t=e_{23}=e_{5}-e_{2}-e_{13} \\
& d p h_{3} / d t=e_{21}=e_{6}-e_{3}-e_{17} \\
& d p h_{4} / d t=e_{19}=e_{8}+e_{12}+e_{13}-e_{20} \\
& d q_{21}=f_{21}
\end{aligned}
$$

The following modelling equations are creating for the electro mechanical part of BLDC motor

$$
\begin{aligned}
& e_{8}=f_{a}(\theta) \cdot K_{T} \cdot f_{7} \\
& e_{8}=f_{a}(\theta) \cdot K_{T} \cdot f_{7} \\
& e_{8}=f_{a}(\theta) \cdot K_{T} \cdot p h_{1} / L_{a}
\end{aligned}
$$

Where $f_{7}=f_{25}$ is a common flow junction.

$f_{a}(\theta)$ : Trapezoidal function for A phase.

$f_{a}(\theta) . K_{T}$ : modulus of gyrator element for torque.

$K_{T}$ : Torque constant.

$e_{9}=f_{b}(\theta) \cdot K_{E} \cdot f_{10}$

$e_{9}=f_{b}(\theta) \cdot K_{E} \cdot f_{22}$

$e_{9}=f_{b}(\theta) \cdot K_{E} \cdot p h_{4} / J$

Where $f_{10}=f_{22}$ : common flow junction

$f_{a}(\theta) \cdot K_{E}$ modulus of gyrator element for back emf of phase A

$K_{E}$ Back emf constant

First, the definition of the elements is important to know what they give to the system. F's and e's are the flows and efforts of the bond graph. Ph1, ph2, ph3 are the electrical activity in the three phases. Ph4 is the Angular activity of the rotor. $\mathrm{Ra}, \mathrm{Rb}, \mathrm{Rc}$ are the resistance in the three phases. $\mathrm{Rf}$ is the friction resistance. $\mathrm{La}, \mathrm{Lb}, \mathrm{Lc}$ are the inductance of the three phases.

The trapezoidal function of the rotor position is:

$$
\begin{aligned}
& f_{a}(\theta)=1 ; \text { if }(0>\theta>2 . p i / 3) \\
& f_{a}(\theta)=1-(\theta-2 . p i / 3) * 6 / p i ; \text { if }(2 . p i / 3>\theta>p i) \\
& f_{a}(\theta)=1 ; \text { if }(p i>\theta>5 p i / 3) \\
& f_{a}(\theta)=-1+(\theta-5 . p i / 3) * 6 / p i ; \text { if }(5 . p i / 3>\theta>2 . p i)
\end{aligned}
$$

Similarly, trapezoidal functions for the other two phases.

$$
\begin{aligned}
& f_{b}(\theta)=f_{a}(\theta-2 . p i / 3) \\
& f_{c}(\theta)=f_{a}(\theta-4 . p i / 3)
\end{aligned}
$$

The same:

$$
\begin{aligned}
& e_{13}=f_{b}(\theta) \cdot K_{E} \cdot f_{17} \\
& e_{17}=f_{b}(\theta) \cdot K_{E} \cdot f_{18} \\
& e_{12}=f_{b}(\theta) \cdot K_{T} \cdot f_{11} \\
& e_{16}=f_{b}(\theta) \cdot K_{T} \cdot f_{15}
\end{aligned}
$$




\section{SIMULATION OF BLDC MOTOR MODEL}

The simulations are done in LabVIEW using control and simulation loop using the default solver ode (Runge-Kutta 1). The simulation time has been taken infinity to shows that the controller will respond in real time to the command and changing the load in range of the named torque will be Compensated by controller and maintains on the speed command.

TABLE 2. PARAMETERS FOR SIMULATION [10].

\begin{tabular}{|l|l|l|l|}
\hline Parameter & Symbol & Value & Unit \\
\hline Moment of Inertia & $\mathrm{J}$ & 0.0002 & $\mathrm{Kg} . \mathrm{m}^{2}$ \\
\hline Inductance of stator & $\mathrm{L}$ & 0.0272 & $\mathrm{H}$ \\
\hline Resistance of stator & $\mathrm{R}$ & 0.7 & $\mathrm{Ohms}$ \\
\hline Friction & $\mathrm{F}$ & 0.2 & $\mathrm{~N} . \mathrm{m} . \mathrm{s}$ \\
\hline Back EMF constant & $\mathrm{Kb}$ & 0.513 & $\mathrm{~V} / \mathrm{Rad} / \mathrm{Sec}$ \\
\hline Number of Poles Pairs & $\mathrm{P}$ & 2 & \\
\hline Motor Torque constant & $\mathrm{Ke}$ & 0.1 & $\mathrm{Kg} \cdot \mathrm{m} / \mathrm{A}$ \\
\hline
\end{tabular}

As can be seen form fig. 5, the back-emf waveform is trapezoidal and it is biased of each phase 120 degrees as well. The trapezoidal shape of the back-emf is important in BLDC motor in order to obtain linear relationship between torque produced by the rotor and the current.

Fig. 6 shows the speed of the BLDC motor in the open loop system. It is clear that the speed takes about 0.08 seconds to reach $75[\mathrm{rad} / \mathrm{sec}]$. and it is clear that the system speed is stable and it can be controlled.

\section{Back EMF}

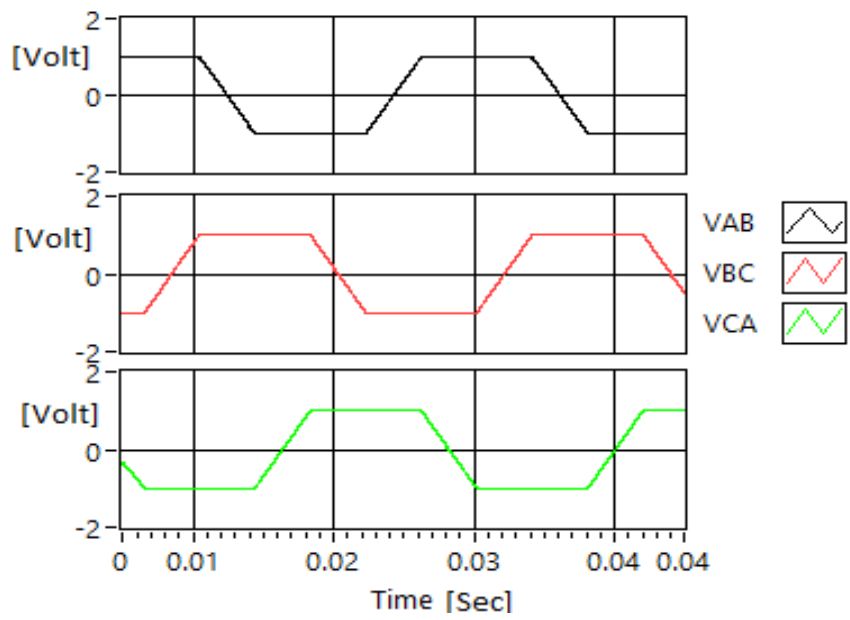

Fig. 5: Back-EMF Waveform

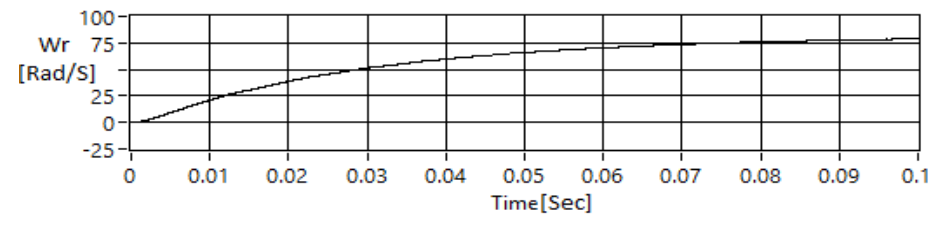

Fig. 6: open-loop speed respond in respect of time

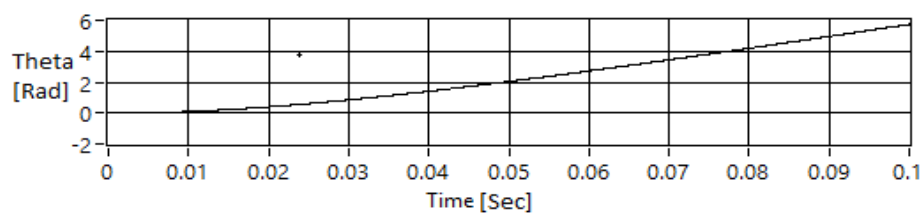

Fig. 7 The angular displacement of the BLDC motor's rotor

Fig. 7 shows the angular displacement is increasing while the motor's rotor is rotating, and it is clear that position-time relation is not linear and that because the speed of the motor is not steady yet; Nevertheless, the relation will become linear as the acceleration become zero and the speed in the steady state.

The shape and the general appearance of the different plot result which are obtained from the model is an evidence that bond graph model of the motor is appropriate.

\section{BLDC MOTOR CONTROL}

PID control is a proportional integral plus derivative controller whose transfer function is:

$$
G_{P I D}(s)=K_{p}+\frac{K_{i}}{s}+K_{d} s
$$

PID controller is conceded one of the simplest controller and easy to be applied and does not require high performance microprocessors. The PID gains can be obtained using many different methods like zero-pool cancelation, Ziegler-Nichols, and trial and error. In this paper, Trial and error method has been used in order to tune the PID controller. PI controller was enough to control the motor speed as it is demonstrated in fig. 8.

Fig. 9 shows the command of the brushless DC motor speed. It is a step signal with $50[\mathrm{Rad} / \mathrm{Sec}]$ initial value and It is changed at $0.02 \mathrm{Sec}$ in order to test the speed respond on the $20 \mathrm{Rad} / \mathrm{sec}$ angular speed.

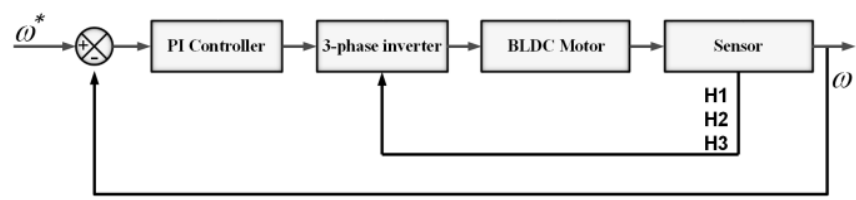

Fig. 8: The block diagram of the closed loop system 


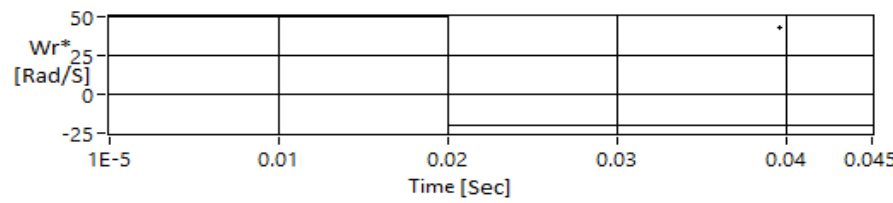

Fig. 9: The speed command for the BLDC Motor.

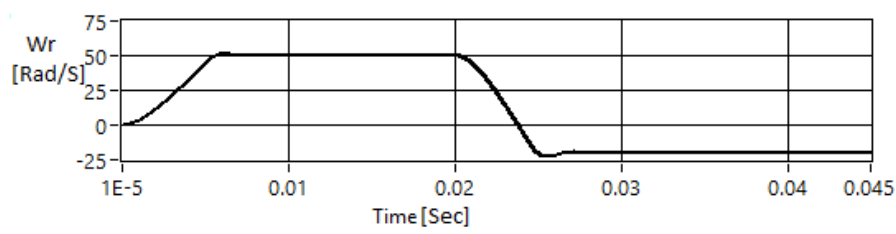

Fig. 10: Motor Speed respond with controller.

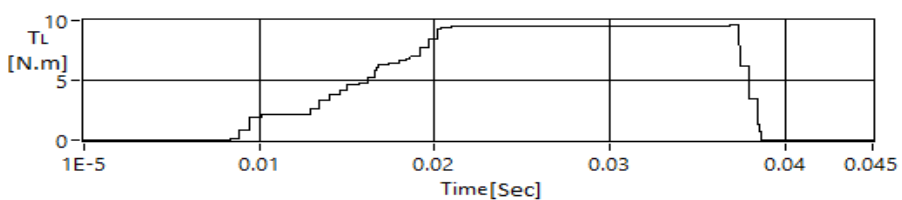

Fig. 11: Changing the load torque manually.

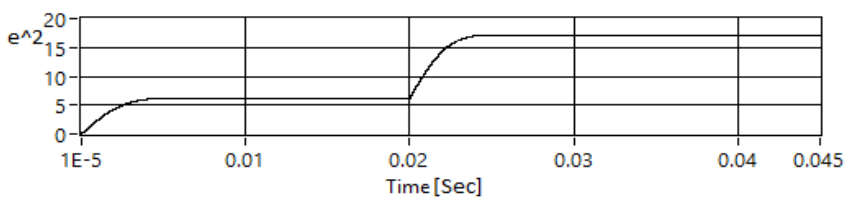

Fig. 12: integration of error square.

Fig. 10 illustrates the success of the PI controller in tracking the speed command, where it took less than 0.01 to reach the reference speed. There was a small overshoot in the speed respond; However, it was less than $5 \%$ of the speed command value. From both figures 10 and 11, it is clear that the changes of load torque did not affect the speed respond, which means that the controller was able to compensate the torque changes and maintains on the reference speed.

$$
\operatorname{error}\left(\omega_{r}\right)=\int\left(\omega_{r}^{*}-\omega_{r}\right)^{2} d t
$$

Fig. 12 shows the integration of the error square in respect of time as it is clarified in equation 31 . The integration of error increase gradually about $5 \mathrm{~ms}$ to become constant, which means the error decrease to zero (control successes)

\section{CONCLUSIONS}

This paper presented the Bond Graph representation of a Brushless DC Motor and the inverter used to drive this motor. The simulation result obtained for the motor's model presented all the phenomena expected of BLDC motor and were satisfactory after the simulation analysis.

The LabVIEW results show success of the speed control and fast dynamic response for the BLDC which was modeled using Bond Graph method. Indeed, classical modeling methods requires more mathematical equations. The aim of this paper was to obtain model that would be simple, precise, can be modified easily and suitable for real time implementation. The LabVIEW results of this paper have shown that these goals have been fulfilled. In this work, Bond Graph modeling method was used to model three phase BLDC motor and its drive circuit that was used, analyzed, and extended, for overcoming the difficulties of the classical modeling method.

\section{REFERENCES}

[1] Atef Saleh Othman Al-Mashakbeh "Proportional Integral and Derivative Control of Brushless DC Motor" ISSN 1450-216X Vol.35 No.2 (2009), pp.198-203

[2] G. H Jang and M.G. Kim. "A Bipolar-Starting and uni polar- running Method to Drive an HDD Spindle Motor at High Speed with Large Starting Torque." IEEE Transactions on Magnetics (2005). 41(2):750755, Feb.

[3] E.Grochowski and R.F Hyot. "Future trends inhard disk drives" IEEE Tran.On Magnetics (1996).32(3):1850-1854,May.

[4] Anand Vaz, S.S.Dhami and Sandesh Trivedi " Bond Graph Modeling and Simulation of Three phase PM BLDC Motor" NIT, Durgapur, India, December 17-18, 2009 NaCoMM-2009-ASMD2

[5] P.C.Sen. "Principles of Electric Machines and Power Electronics". John Wiley \& Sons, 1997.

[6] Jan F. Broenink, "Introduction to Physical Systems Modelling with Bond Graphs", Control Laboratory, University of Twente, Netherland, 1999, pp. 1-31.

[7] Renato Ferreira Simao, Nestor Roqueiro, Luis Ignacio Silva, Cristian Hernan de Angelo "Bond Graphs Representation of a Brushless DC Motor and Inverter Driver" 27-31 Oct. 2013 ISSN: 2175-8603.

[8] Balogh Tibor, Viliam Fedák, František Durovský "Modeling and Simulation of the BLDC Motor in MATLAB GUI" 27-30 June 2011 INSPEC: 12207213

[9] Rutuja A Bhat, Pallavi S. Jadhav "Modeling and simulation of BLDC motor in electric power steering by using MATLAB" 7-8 Jan. 2016 INSPEC: 164294.

[10] Santanu Mondal, Arunabha Mitra, Madhurima Chattopadhyay "Mathematical modeling and simulation of Brushless DC motor with ideal Back EMF for a precision speed control" IEEE International Conference on Electrical Computer and Communication Technologies (ICECCT-2015), ISBN 978-1-4799-6084-2. 